\title{
A MODEL FOR SNOW-SLAB FAILURE UNDER CONDITIONS OF DYNAMIC LOADING
}

\author{
By Jerome B. Johnson* \\ (Oceanographic Services, Inc., P.O. Box 6783, Santa Barbara, California 931 ir, U.S.A.)
}

\begin{abstract}
A stress-wave model is used to describe snow-slab failure under dynamic loading conditions. This model indicates that dilational waves and shear waves can interact with a thin, weak bedding layer underlying a snow slab causing dilatational and shear stresses in the layer. The magnitude and distribution of stresses in the layer are shown to depend strongly on the height of the loading source above the bedding plane, the difference in impedance between the slab and the loading source, the difference in impedance between the slab and its substratum, and the initial stress magnitude of the loading source. Failure occurs in the bedding layer when the generated stresses exceed the strength of the layer. This causes a loss of shear strength capacity at the bedding plane and a re-distribution of stress in the slab. If the shear capacity is reduced sufficiently the body-force loading of the slab will cause snow-slab failure.

RÉsUMÉ. Un modèle pour la rupture de plaque de neige sous les conditions de charge dynamique. On utilise un modèle d'onde de compression pour décrire la fracture d'une plaque de neige sous une charge dynamique. Ce modèle indique que des ondes de dilatation et des ondes de cisaillement peuvent interagir avec une mince couche de base peu cohérente située sous une plaque de neige pour provoquer des efforts de dilatation et de cisaillement dans la couche. On montre que la grandeur et la distribution des efforts dans la couche dépendent beaucoup de la hauteur et de la charge au-dessus du plan de glissement, de la différence entre les impédances de la plaque et de la charge, de la différence entre les impédances de la plaque et de son substrat et de la grandeur initiale de l'effort et de la charge. La rupture se produit dans la couche de base lorsque les contraintes engendrées excèdent la résistance de la couche. Ceci engendre une perte de résistance au cisaillement le long du plan de glissement et une redistribution des efforts dans la plaque. Si la capacité de résistance au cisaillement est suffisamment réduite, le poids de la plaque elle-même provoque la rupture.

Zusammenfassung. Ein Modell für den Bruch von Schneebrettern unter dynamischer Belastung. Zur Beschreibung des Bruches von Schneebrettern unter dynamischer Belastung wird ein Druckwellenmodell herangezogen. Es zeigt, dass Dehnungs- und Schwerwellen in einer dünnen und schwachen Grundschicht eines Schneebrettes Dehnungs- und Scherspannungen hervorrufen können. Grösse und Verteilung der Spannungen in der Schicht erweisen sich als stark abhängig von der Höhe der Druckquelle über der Auflagefläche, vom Impedanzunterschied zwischen dem Brett und der Druckquelle, vom Impedanzunterschied zwischen dem Brett und seinem Untergrund sowie von der ursprünglichen Grösse der Druckquelle. Ein Bruch in der Grundschicht tritt ein, wenn die erzeugten Spannungen die Festigkeit der Schicht übersteigen. Dies führt zu einem Verlust an Scherfestigkeitskapazität an der Auflagefläche und zu einer Neuverteilung der Spannungen im Brett. Wird die Scherkapazität ausreichend vermindert, so bricht das Brett unter der Last seiner eigenen Schwere.
\end{abstract}

\section{INTRODUGTION}

Every year a large number of slab avalanches are released by the dynamic loads which result from falling snow cornices, explosive charges, sonic booms, and other sources. The mechanisms by which dynamic loads release avalanches are not well understood at present. Previous explanations for snow slab failure under conditions of dynamic loading are based on field observations and rock-blasting technology. These explanations consider the mechanical fracturing of the slab, caused by surface or interior craters, as being an important slab-failure mechanism. It has also been thought that surface dynamic loads increase briefly the normal and down-slope shear stresses acting on a snow slope and give rise to slab failure. Stress waves propagating within the snow slope have not so far been considered as an important influence (Mellor, I968, I973; Perla and Martinelli, 1976); however, recent experimental and theoretical work by the present author indicates that stress waves may be an important triggering mechanism for snow-slab failure.

This paper reviews the important factors which govern snow-slab failure and demonstrates how such failure can be initiated by stress waves. The important features of stress-wave interactions with snow that apply to the slab-failure model are considered, and the response

* Formerly at: Geophysics Program, University of Washington, Seattle, Washington 98195, U.S.A. 
characteristics of snow to stress-wave loading are used to develop a stress-wave failure model for slabs. The theory is then utilized to illustrate important factors which should be considered in avalanche control.

\section{General Response of SnOW to stress-WAve LOADING}

There are many interrelated stress-wave propagation phenomena that may be used to show how snow reacts to a dynamic load. The controlling features of stress-wave-snow interaction that are important to snow-slab failure include: the kinds of stress waves, the impedance, cratering, and crack propagation, spherical stress waves, and stress-wave propagation in layered media.

\section{Kinds of stress waves}

The kinds of stress waves in snow resulting from dynamic loads have recently been reviewed by Johnson (unpublished). A model of an elastic porous material filled with fluid was used to describe stress-wave propagation. This model and supporting experimental evidence demonstrated that three kinds of waves may propagate in snow: two dilational waves and a shear wave. In homogeneous, isotropic snow the propagation characteristics of the three waves are decoupled from one another but involve coupled motion between the fluid and solid. The dilatational wave of the first kind (fast wave) and a shear wave move through the solid ice frame. They would occur even if the snow were in a vacuum. As fast waves and shear waves propagate in the ice frame they interact with the fluid-filled pores causing a secondary motion in the fluid. The dilatational wave of the second kind (slow wave) propagates in the fluid-filled pores and interacts with the ice frame to produce motion in the solid. The slow wave is highly attenuated because of frictional losses and this rapid attenuation results in a rapid loss of energy for slow waves near the dynamic loading surface. Energy transmission by the stress wave over any significant distance must, therefore, be the result of dilatational waves of the first kind and shear waves. Slow waves are, therefore, not considered to contribute to slab failure which is stress-wave induced.

\section{Impedance}

The manner in which stress waves propagate, reflect, transmit, and dissipate energy in snow is described by the impedance and propagation constants of the snow.

The snow impedance is defined as a complex ratio of stress to particle velocity at a point. If it is independent of position the impedance is termed the wave impedance $W$ and it describes the resistance associated with energy dissipation and the reactance which results from the effective mass and stiffness of snow. In snow, impedance is strongly influenced by the air permeability, density, and elastic properties of the sample.

The propagation constant is a complex constant which describes the propagation velocity and energy dissipation of a stress wave at a given frequency. It also describes the rapidity of stress-wave propagation and attenuation within a material, whereas impedance determines the magnitude of transmitted and reflected energy between materials of differing impedance. The impedance of the dynamic loading source and of the snow determines the loading history for a snow slab.

\section{Cratering}

Cratering complicates the loading history for a snow slope during dynamic loading. If a dynamic load is of low enough magnitude and no surface craters form in the snow surface, then classical methods can be used to describe the loading. However, if cratering occurs, the energy exchange between a source and snow becomes much more complicated. As the crater 
is being formed, the impedance mismatch between the source and the snow continually changes because of compaction and fracturing in the snow. Additionally, large amounts of energy are lost during crater formation from viscous damping, melting, fracturing, ejection of material from the crater, and possibly other mechanisms. The continuous change of impedance mismatch and the mechanisms by which energy is dissipated during crater formation result in an extremely non-linear loading history for snow.

\section{Crack propagation}

The interaction of stress waves and snow does not end with the transmission of energy or crater formation. The region immediately beyond a crater zone is generally surrounded by a small, roughly hemispherical, region of cracks radiating from the point of loading. These cracks are produced by tensile stresses which are set up by outgoing spherical compression waves parallel to the wave front. The radial cracks extending from the crater region continue to grow until the stress wave passes through the region or its intensity is reduced below the level which will cause tensile failure. These effects have been well documented for snow (Fuchs, 1957; Mellor, 1965, 1968, 1973; Livingston, 1968) and are similar for other materials as well (Kolsky, I953; Cristescu, I967; Kolsky and Rader, 1968). Cracks have been observed to form concentrically to the point of loading in low-density snow (personal communication from H. Gubler, 1979).

The tensile fractures caused by high-intensity spherical stress waves differ from the fractures which occur when a specimen is stressed statically. This difference is because the stress wave loads any given point in the snow for a very short time. Any cracks that result from such stress-wave loading do not have time to propagate. Instead of forming long running cracks, a large number of separate fractures form and these sometimes join up to form a continuous irregular surface (Kolsky, 1953). Crack-tip velocities for many materials are about one-third the propagation velocity of compressional stress waves (Kolsky and Rader, 1968). If we assume crack-tip velocities for snow are also one-third that of the compression-wave propagation velocity, then a simple expression relating crack length to the duration of loading can be formulated:

$$
C_{\mathrm{L}}=0.5 C_{0} \Delta t
$$

where $C_{\mathrm{L}}$ is the crack length, $C_{0}$ is the propagation velocity for compressional stress waves, and $\Delta t$ is the period of time during which the stress is greater than the tensile strength of snow. Since $C_{0}$ is a constant for a given snow type, $\Delta t$ must determine the crack length. Short-period dynamic loads result in small crack lengths while static loads (large $\Delta t$ ) result in cracks which propagate throughout the snow slope. This implies that when a large fracture area is needed to maximize the mechanical damage in a material, as in snow cornice removal or rock blasting, a long-duration dynamic load would be preferred to an extremely rapid load; fractures can only spread in this way.

\section{Spherical stress waves}

As a spherical wave continues to propagate radially through the snow, its stress magnitude decreases due to viscous damping and geometrical spreading. The spherical stress waves propagating through the snow can be described in cylindrical coordinates by the equations:

$$
\begin{aligned}
\sigma_{z z} & =\int_{0}^{\infty}\left[A\left(\psi-q^{2} / \psi\right) q+2 \mathcal{N} \psi q\right] \mathcal{J}_{0}(q r) \exp (-\psi z) \mathrm{d} q, \\
\sigma_{z r} & =2 \mathcal{N} \int_{0}^{\infty} \mathcal{F}_{\mathrm{I}}(q r) q^{2} \exp (-\psi z) \mathrm{d} q
\end{aligned}
$$


where $\sigma_{z z}$ is the dilatational stress parallel to the $z$-axis and $\sigma_{z r}$ is the shear stress along plane sections parallel to the snow surface, $A$ and $\mathcal{N}$ are Lamé coefficients for snow, $\psi^{2}=q^{2}-\delta^{2}$, $q$ and $\delta$ are wave numbers. The coordinate system used to describe the plane sections in snow and snow-slab nomenclature is shown in Figure I. Equations (2) and (3) describe the spatial distribution of stresses along plane sections in homogeneous snow. $z$ is the distance from the source and $r$ is the distance along the plane (Fig. I). Figure 2 shows the variation of the dilatational stress magnitude $\left|\sigma_{z z}\right|$ on planes located at $z=0 . \mathrm{I}, \mathrm{I}$.0, and 2.0 from a given plane ( $z$ in arbitrary units). The initial stress was arbitrarily chosen and $\delta$ was set equal to 6o. It is apparent that the maximum dilatational stress along the plane is directly beneath the source. The dilatational stress decreases from the maximum along the plane as $r$ increases. As the distance $z$ between the source and plane is increased, $\left|\sigma_{z z}\right|$ decreases less rapidly with $r$

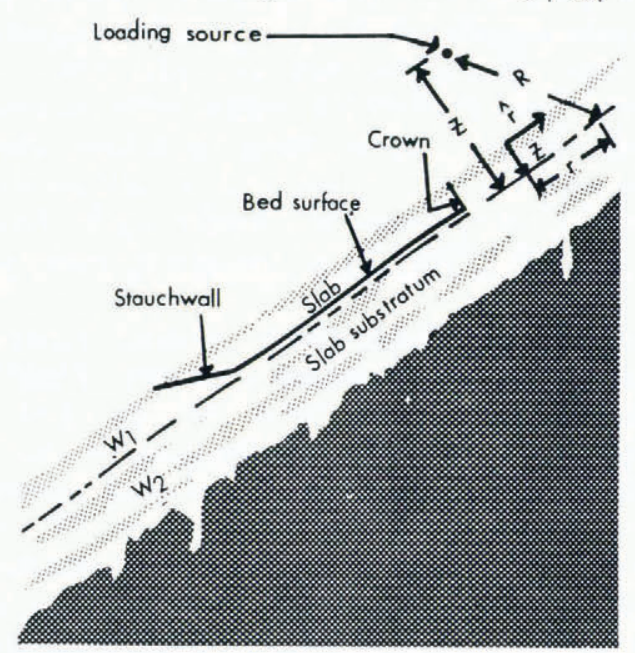

Fig. I. Nomenclature for a snow slab and the cylindrical coordinate system used to describe stress-wave propagation in snow.

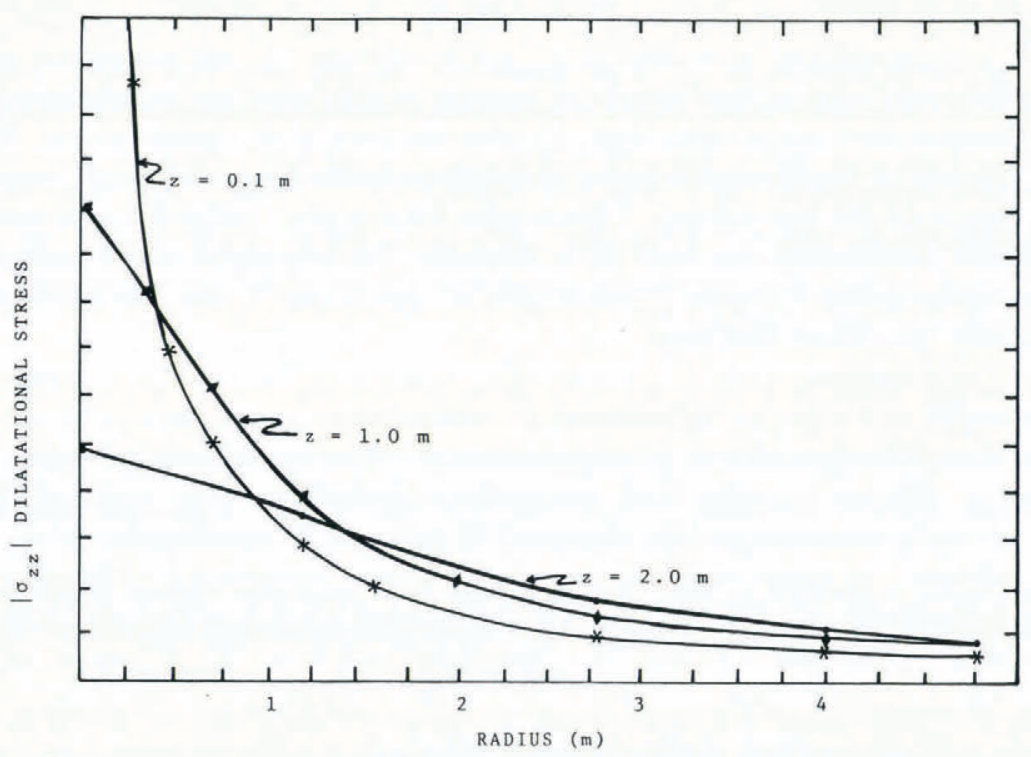

Fig. 2. Dilatational stress magnitude on plane layers in an infinite homogeneous snow medium, for various loading source elevations and spherical waves. 
than at smaller values of $z$. The shear-stress magnitude $\left|\sigma_{z r}\right|$ with $\delta=60$ is shown in Figure 3 . The shear-stress magnitude is zero directly beneath the loading source, that is at $r=0$, and passes through a maximum as $r$ increases. The rate of change of $\left|\sigma_{z r}\right|$ as $r$ increases past the maximum shear stress is determined by the distance of the loading source from the loading plane.

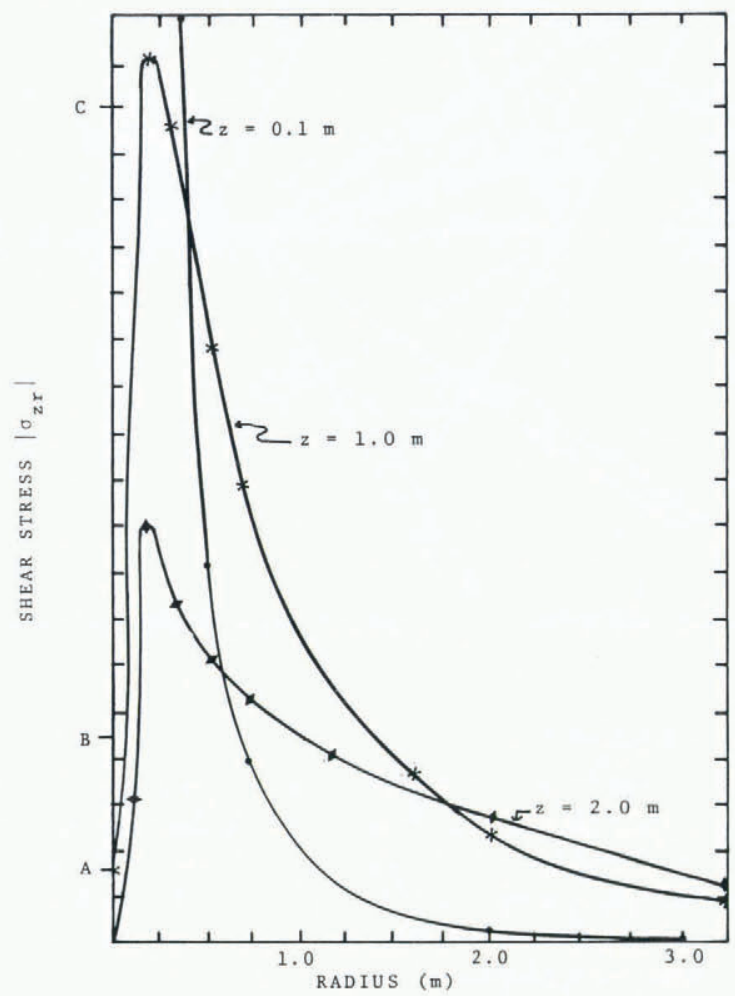

Fig. 3. Shear-stress magnitude on plane layers in an infinite homogeneous snow medium for various loading-source elevations and spherical waves.

\section{Anisotropic considerations}

In order to complete the description of stress-wave propagation in snow, some consideration must be given to the anisotropic properties of snow. This anisotropy can be fairly accurately described by considering snow to be a layered material. The physical characteristics of the layers may vary from one another but are considered to be homogeneous and isotropic within the layer. Stress-wave propagation, reflection, and transmission in each layer is controlled by the impedance and propagation constants of that layer. The manner in which a compression wave is reflected and refracted at a layer boundary interface is shown in Figure 4. Both shear and dilatational waves are generated at the boundary. The magnitudes of the reflected and refracted stress waves are determined by the impedance difference $\left(W_{1}-W_{2}\right)$ between the two snow half-spaces. If $W_{1}=W_{2}$ then no reflection occurs and the stress wave is totally transmitted. When there is an impedance mismatch between the layers the stress magnitude at the interface will be the sum of the incident and reflected dilatational and shear waves. Thus, the stresses are greater along such an interface than would be found in homogeneous snow.

Since stresses are greater along such an interface, we would expect that stress waves could cause a snow slab to fail along a lithological boundary. 


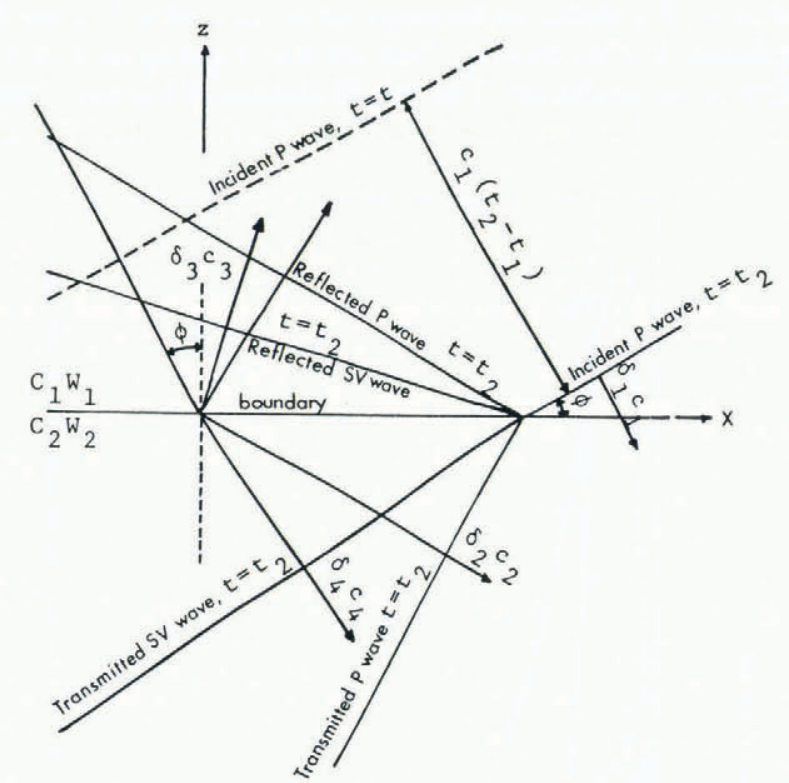

Fig. 4. Reflection and refraction of an incident plane compressional wave at a boundary.

\section{STRESS-WAVE-INDUGed SNOW-SLAB FAILURE}

Any description of snow-slab failure resulting from a dynamic load must be consistent with observed slab failures and take into account the characteristics unique to snow slabs. Recent theories of snow-slab failure emphasize the importance of the bonding strength between a snow slab and its substratum and the resulting shear capacity at the bed of the slab. Field observations tend to support the belief that snow slabs fail along a weakly bonded layer between the slab and substratum (Moore, unpublished; Perla and Martinelli, 1976; Perla, 1977).

Snow slabs have been observed to fail under widely varying dynamic-loading conditions. Snow cornice falls and explosives detonated on the snow surface form craters in the snow and are effective means for releasing snow slabs. Sonic booms and explosives detonated above the snow surface are also effective at releasing slab avalanches but cause little or no cratering (LaChapelle, I96o; Martinelli, I972; Mellor, I973; Perla and Martinelli, I976; Gubler, 1977). These observations suggest that fractures in the crater area are not necessary for the initiation of slab avalanches.

When considering how a dynamically-loaded snow slab will fail, all possible supporting sources for that slab must be accounted for. A snow slab is supported along its bedding plane, crown, stauchwall, and flanks. The importance of these supporting regions in the prevention of slab failure may vary depending on the structure of the slab and type of snow involved. For example, a soft slab may receive a large percentage of its total support strength from the bedding plane. In contrast, a hard slab may have the majority of its support strength in the crown, flanks, and stauchwall regions. The distribution of the total support strength of a slab between its various supporting regions determine the effectiveness of stress-wave-induced slab failures.

The characteristics of stress-wave propagation through snow and the interaction at interfaces indicate that snow slabs with a weak bedding layer and well-defined layers should be most susceptible to dynamic-loading failure. Extremely hard snow slabs that are strongly supported in the crown, flanks, and stauchwall regions are not as readily influenced by stress- 
wave loading. In these regions there are no distinct weak boundary layers for stress-wave interaction.

Stress-wave-induced snow-slab failure begins with the transmission of spherical stress waves into the slab from a dynamic-loading source. If the spherical stress waves (given by $\left|\sigma_{z z}\right|$ and $\left|\sigma_{z r}\right|$ in Equations (2) and (3)) exceed the shear or dilatational strength of snow, failure will occur in that region. Two factors increase the probability that such failure will occur in the bedding layer: a strong discontinuity interface is usually present between a slab and its substratum, and generally there is a weak bedding layer bonding the slab to the substratum. The strong discontinuity interface between the slab and substratum results in an enhancement in stresses at the boundary. Failure in the bedding layer reduces the shearstrength capacity of the bedding plane. If the shear capacity is reduced sufficiently, the bodyforce stresses in the slab will be re-distributed causing snow slab failure. This subsequent failure can be explained by any number of existing theories (Perla and LaChapelle, 1970; Brown and others, 1972; Lang and others, 1973; Curtis and Smith, 1973; Perla, [1975]). Craters that are formed in the crown region by an explosive may aid the snow-slab failure mechanism by providing stress concentration points from which tensile cracks can propagate.

The area of failure that develops in the bedding plane determines the shear-strength capacity of the slab. This failure area depends on many interrelated factors: the initial stress magnitude of the loading source, the impedance difference between the loading source and snow surface, the elevation of the loading source above the bedding plane, the strength of the bedding layer, and the impedance difference between the slab and its substratum.

The initial stress magnitude of the loading source and the impedance difference between the source and the snow surface determine the magnitude of stress waves that are transmitted into the snow. If the impedance difference between source and snow is large, then most of the source energy is reflected from the snow surface. This concept can be illustrated by considering a model which assumes two semi-infinite materials in contact, snow and a material identical to that of the loading source, and plane waves normally incident to the boundary interface separating the materials. The power transmission across the boundary is determined by:

$$
Z=\frac{4 W_{e} W_{\mathrm{s}}}{\left(W_{e}+W_{\mathrm{s}}\right)^{2}}
$$

where $W_{\mathrm{s}}$ is the wave impedance of the snow and $W_{e}$ is the wave impedance of the source. The power associated with the loading source can be determined from the expression:

$$
P=\frac{P_{e}^{2}}{2 W_{e}}
$$

where $P_{e}$ is the initial stress of the source (Kinsler and Frey, 1962). Expressions (4) and (5) can now be combined to find the total power transmitted from the loading source into the snow, $T_{\mathrm{s}}=Z P$.

This transmitted power will ultimately determine the stress loading at the bedding plane. To illustrate how the transmitted power can vary depending on the loading source, we shall examine two explosives typically utilized in avalanche control, "Tetrytol" and straight gelatin (Table I).

Using the information in Table I, we find that the ratio of power transmitted into snow by "Tetrytol" and straight gelatin is

$$
\frac{T_{\mathrm{T}}}{T_{\mathrm{g}}}=\frac{Z_{\mathrm{T}} P_{\mathrm{T}}}{Z_{\mathrm{g}} P_{\mathrm{g}}}=0.54 \times 8.3=4.5 .
$$

This indicates that approximately 4.5 times more power is transmitted into the snow by "Tetrytol". "Tetrytol" has a greater impedance difference with snow, but its initial stress magnitude more than compensates for the impedance mismatch. If a porous-medium model 
Table I. Characteristics of explosives used in aValanche work and snow PROPERTIES ASSUMED FOR THE ELASTIC MODEL

\begin{tabular}{|c|c|c|c|c|}
\hline Explosive* & $\begin{array}{l}\text { Approximate } \\
\text { density } \\
\mathrm{kg} \mathrm{m}^{-3}\end{array}$ & $\begin{array}{c}\text { Approximate } \\
\text { confined } \\
\text { detonation } \\
\text { speed } \\
\mathrm{m} \mathrm{s}^{-1}\end{array}$ & $\begin{array}{c}\text { Detonation } \\
\text { pressure } \\
P_{e}\end{array}$ & $\begin{array}{c}\text { Wave } \\
\text { characteristic } \\
\text { impedance } \\
\mathrm{kg} \mathrm{m}^{-2} \mathrm{~s}^{-1}\end{array}$ \\
\hline $\begin{array}{l}\text { "Tetrytol" } \\
\text { Straight gelatin }\end{array}$ & $\begin{array}{l}1.6 \times 10^{3} \\
1.7 \times 10^{3}\end{array}$ & $\begin{array}{l}7.0 \times 10^{3} \\
3.4 \times 10^{3}\end{array}$ & $\begin{array}{l}\text { 1. } 2 A_{0} \dagger \\
0.3 A_{0}\end{array}$ & $\begin{array}{l}1.12 \times 10^{7} \\
5.78 \times 10^{6}\end{array}$ \\
\hline Material & & $\begin{array}{c}\text { Stress-wave } \\
\text { propagation } \\
\text { velocity } \\
\mathrm{m} \mathrm{s}^{-1}\end{array}$ & & \\
\hline Snow & $3.0 \times 10^{2}$ & $1.0 \times 10^{3}$ & 一 & $3.0 \times 10^{5}$ \\
\hline
\end{tabular}

is used to describe the transmission, then $T_{\mathrm{T}} / T_{\mathrm{g}}$ drops to 2.I (Johnson, unpublished). These findings are supported by field experiences which indicate that fast-detonation-speed, highdetonation-pressure explosives are more effective at triggering avalanches than are slowerburning, low-detonation-pressure explosives (Perla and Martinelli, 1976).

Explosives detonated above a snow slab will create an incident air stress wave that propagates over the slab. This incident air wave will determine the stress transmission into the slab, depending on the elevation of the explosive above the slab and impedance matching. Experimental observations suggest that the incident air stress wave contributes significantly to the stress in the slab (Gubler, I977). This results because stress waves propagating in air attenuate less rapidly than do the stress waves which propagate in the snow-pack.

Two other factors that influence strongly stress-wave-induced slab failure are the effect of source elevation above the bedding plane and the strength of the bedding plane. The elevation $z$ of a loading source with respect to the bedding plane will control the spatial distribution of stress along that plane. A source located close to the bedding plane results in a concentrated stress beneath the source. Conversely, a loading source elevated further away from the bedding plane tends to distribute the stresses more evenly along the bedding layer (Figs 2 and 3). The elevation of a loading source coupled with the strength of the bedding layer can determine the area of failure beneath the slab. This dependence can be seen in Figure 3 where three different shear strength values for the bedding layer have been assumed (shear strengths A, B, C). For a layer with shear strength A, the radius of failure is approximately 4.5 for $z=0$. I, I0.0 for $z=$ I.0, and 12.0 for $z=2.0$. Similarly, a shear strength of B results in failure radii of 3.0 for $z=0.1,6.0$ for $z=1.0$, and 4.0 for $z=2.0$. Finally, for a shear strength of $\mathrm{c}$, the radii of failure are $\mathrm{I} .5$ for $z=0.1,0.5$ for $z=\mathrm{I} .0$, and no failure occurs for $z=$ o.I. In the above examples the source elevation which produced the largest failure area is different for each value of shear strength. The source elevation which produced the greatest failure area is $z=2.0$ for shear strength $\mathrm{A}, z=\mathrm{I} .0$ for shear strength $\mathrm{B}$, and $z=0 . \mathrm{I}$ for shear strength $\mathrm{c}$.

The final factor which influences stress-wave-induced slab failure is the impedance difference between the snow slab and its substratum. This has already been discussed in the previous section.

Although the significance of the factors which influence stress-wave-induced snow-slab failure have been discussed independently of each other, they are strongly interrelated. In order to determine the most effective elevation for a loading source, each of the other factors must be considered as they control the transmission of energy into the slab, the strength of the 
slab, and stress magnitude of the bedding plane. Another problem illustrating these interrelationships is that of determining the area of failure along the bedding plane for an explosive. It is evident that each of the factors plays a role in determining the area of influence and must be considered.

\section{Conclusions}

A failure mechanism resulting from the application of a dynamic load, for example, an explosive, is postulated utilizing a stress-wave model for a sloping snow slab overlying a weaklybonded bedding layer of snow. Calculation of the stresses in the bedding layer demonstrates that stress waves may cause it to fail, resulting in a loss of shear capacity at the bed, a stress redistribution in the slab, and slab failure.

The stress-wave-induced failure mechanism in slab avalanches implies that the following are important considerations in efficient avalanche control:

I. Isolated explosive charges applied to snow slabs are effective avalanche triggers only when the slab is overlying a weakly bonded layer of snow.

2. The number and placement of explosive charges required to initiate slab failure depend on:

(a) the strength of the bedding layer underlying the slab,

(b) the strength at the slab boundaries,

(c) the body-force loading on the bedding layer and boundaries of the slab,

(d) the impedance mismatch between the slab and underlying snow,

(e) the height of the charge above the bedding layer,

(f) the detonation pressure of the explosive, and

(g) the impedance mismatch between the slab and the explosive.

3. The optimum location for an explosive charge is such that the region of failure in the basal layer lies within the slab boundaries. The largest shear-capacity loss and subsequent stress re-distribution in a slab will result when the charge is placed below the crown region toward the middle of the slab.

4. Wet snow slabs are not easily released using explosives due to their strongly sintered structure and limited period of instability. These slabs may be released while in a stable state by placing numerous charges throughout the slab and igniting them either sequentially or simultaneously as described by Kobayashi (1978).

\section{REFERENCES}

Brekhovskikh, L. M. 1957. Volny $v$ sloistykh sredakh [Waves in layered media]. Moscow, Akademiya Nauk SSSR. [English translation by D. Lieberman, edited by R. T. Beyer, New York, Academic Press, I96o.]

Brown, C. B., and others. 1972. Slab avalanching and the state of stress in fallen snow, [by] C. B. Brown, R. J. Evans, and E. R. LaChapelle. Journal of Geophysical Research, Vol. 77, No. 24, p. 4570-80.

Cristescu, N. 1967. Dynamic plasticity. Amsterdam, North-Holland Publishing Co.

Curtis, J. O., and Smith, F. W. 1973. Material property and boundary condition effects of stresses in avalanche snowpacks. U.S. Dept. of Agriculture. Forest Service. General Technical Report RM-3, p. 14-23.

Ewing, W. M., and others. 1957. Elastic waves in layered media, by W. M. Ewing, W. S. Jardetzky, and F. Press. New York, McGraw-Hill Book Co., Inc.

Fuchs, A. 1957. Effects of explosives on snow. U.S. Snow, Ice and Permafrost Research Establishment. Special Report 23.

Gubler, H. 1977. Artificial release of avalanches by explosives. Fournal of Glaciology, Vol. 19, No. 81, p. 419-29.

Johnson, J. B. Unpublished. Stress waves in snow. [Ph.D. thesis, University of Washington, 1978.]

Kinsler, L. E., and Frey, A. R. 1962. Fundamentals of acoustics. New York, John Wiley and Sons, Inc.

Kobayashi, F. 1978. The time delay method of avalanche control. Canada. National Research Council. Associate Committee on Geotechnical Research. Technical Memorandum No. 120, p. 50-55.

Kolsky, H. r 953 . Stress waves in solids. Oxford, Clarendon Press. [Reprinted, New York, Dover, I963.]

Kolsky, H., and Rader, D. I968. Stress waves and fracture. (In Liebowitz, H., ed. Fracture: an advanced treatise. Vol. 1 . New York, Academic Press, p. 533-69.) 
LaChapelle, E. R. 1960. Recent progress in North American avalanche forecasting and control. Fournal of Glaciology, Vol. 3, No. 28, p. 679-85.

Lang, T. E., and others. 1973. Buckling characteristics of a sloping snow slab, [by] T. E. Lang and R. L. Brown, W. F. St Lawrence and C. C. Bradley. Fournal of Geophysical Research, Vol. 78, No. 2, p. 339-5I.

Livingston, C. W. 1968. Explosions in snow. U.S. Cold Regions Research and Engineering Laboratory. Technical Report 86.

Martinelli, M., jr. 1972. Simulated sonic boom as an avalanche trigger. U.S. Dept. of Agriculture. Forest Service. Research Note RM-224.

Mellor, M. 1965. Explosions and snow. U.S. Cold Regions Research and Engineering Laboratory. Cold regions science and engineering. Hanover, N.H., Pt. III, Sect. A3a.

Mellor, M. 1968. Avalanches. U.S. Cold Regions Research and Engineering Laboratory. Cold regions science and engineering. Hanover, N.H., Pt. III, Sect. A3d.

Mellor, M. 1973. Controlled release of avalanches by explosives. U.S. Dept. of Agriculture. Forest Service. General Technical Report RM-3, p. 37-49.

Moore, M. B. Unpublished. Weather and snowpack developments associated with avalanching in the Washington Cascades. [M.S. thesis, University of Washington, 1975.]

Perla, R. I. [1975.] Stress and fracture of snow slabs. [Union Géodésique et Géophysique Internationale. Association Internationale des Sciences Hydrologiques. Commission des. Neiges et Glaces.] Symposium. Mécanique de la neige. Actes du colloque de Grindelwald, avril 1974, p. 208-21. (IAHS-AISH Publication No. 114.)

Perla, R. I. 1977. Slab avalanche measurements. Canadian Geotechnical fournal, Vol. 14, No. 2, p. $206-13$.

Perla, R. I. Unpublished. The slab avalanche. [Ph.D. thesis, University of Utah, I971.]

Perla, R. I., and LaChapelle, E. R. 1970. A theory of snow slab failure. Fournal of Geophysical Research, Vol. 75, No. 36 , p. 76 19-27.

Perla, R. I., and Martinelli, M., jr. 1976. Avalanche handbook. U.S. Dept. of Agriculture. Forest Service. Agriculture Handbook 489 . 